-Davetli Yazı $\cdot$ Invited Paper -

\title{
The Amazing, Performing Film: Some Propositions*
}

\author{
Adrian Martin
}

\section{Prologue: Chosen Moments}

Tex Avery possessed a sense of excess in everything and of its organization, which distinguish his films from the stereotyped frenzy characteristic of the majority of American cartoons. Two characters hurtle off a cliff uttering horrendous screams; during shot after shot they fall toward the camera and their repeated cries become unbearable; the scene lasts for only about ten seconds but appears to go on forever. Then they finally land, light as feathers, and the chase resumes as if nothing had happened.

- Noël Burch ${ }^{1}$

F For Fake (Orson Welles, 1974): at the start, the film presents a declaration - spoken and shown - to the effect that, although it is wholly concerned with tricks and tricksters, for the next sixty minutes only the truth will be told and presented. The film eventually winds around to a particularly outlandish story involving Pablo Picasso and his dealings with a mysterious model (Oja Kodar). Welles subsequently reappears on screen to ask whether we are still

\footnotetext{
*E-mail: adrian.martin@monash.edu

Film Critic/ Associate Professor - Monash University

Invited papers are not peer reviewed.

Davetli yazılar hakem değerlendirmesinden geçmemektedir.

DOI: $10.31122 /$ sinefilozofi.426841

Received - Geliş Tarihi: 08.05.2018
} 
believing him and his film. If so, he informs us, we should note that the sixty minutes ended seventeen minutes previously, and that he has been lying his head off ever since.

Gloria (John Cassavetes, 1980). As Gloria (Gena Rowlands), out on the street, is being bugged by (and trying to get rid of) little Phil (John Adames), she is simultaneously aware that a bunch of gangsters in a car are cruising them, with likely murderous intent. The scene plays out to the point where Gloria, suddenly, produces a gun we didn't know she had on her, strikes a Dirty Harry-style pose (immortalised in the film's best known publicity image), and starts expertly blasting the crooks. There is bloodshed, the car skids off, carnage, a dramatic pause; then Gloria looks around the street and, in a perfectly everyday way, calls "Taxi!" Only then does Bill Conti's dramatic orchestral score re-enter.

Raiders of the Lost Ark (Steven Spielberg, 1981). The best known bit of business in this film involves a flashy display of Arabic swordplay versus the no-nonsense, American response from Indiana Jones (Harrison Ford): a gun blast. Whatever we may make of the dire geopolitical significance of this moment, I shall never forget the uproarious response it elicited from the large audience with whom I saw it, on first release in a big cinema.

The Thing (John Carpenter, 1982). A head comes off a mutilated corpse, slithers to the ground, sprouts spider-like legs, and scuttles away. All characters watch in sheer terror, until one of them breaks the ice with the comment: "You gotta be fucking kidding!"

Ferris Bueller's Day Off (John Hughes, 1986). This teen movie is structured around the running, into-camera spiel by its young hero, Ferris (Matthew Broderick) - the kind that takes us back to the camera-complicities of early burlesque performers such as Fatty Arbuckle. During an action-comedy montage sequence where Ferris is running, rushing to get home as quickly as possible, he speeds through a lawn - entering and exiting the frame - where two girls are relaxing. But the camera holds on these girls, and eventually, sure enough, Ferris comes strolling back into the picture to introduce himself: "Hi, I'm Ferris Bueller".

City of Pirates (Raúl Ruiz, 1983). The genre of the surrealist gag - prompting a fou rire to match its amour fou - could be traced across many different kinds of films, directors, periods and nations. In this film, a sequence of shots that seem to become more and more bizarre in their angle and orientation culminates in an absolutely wacky framing from inside a character's mouth, teeth and gums gaping and flapping open in a deliberately tacky special effect - while perfectly somber, ominous music (by Jorge Arriagada) plays on the soundtrack.

Big Trouble in Little China (John Carpenter, 1986). This is perhaps the first major American action-comedy to show clear signs of influence from Hong Kong popular cinema. In a characteristic sequence, it breaks the tone of a string of very serious reaction shots when the last guy in line does an absurdly comic, pantomime-like gesture with his raised eyebrows.

Aliens (James Cameron, 1986). Ripley (Sigourney Weaver) suddenly reappears during the finale, after we have been artfully distracted from concentrating on her exact position in the scene by the spectacle of a threatened girl, Newt (Carrie Henn). Now, clad in her huge, mechanical, "exosuit" armour, she hurls her punchline: "Get away from her, you bitch!" 


\section{Part I: Approaching Film Performance}

\section{Film Performance and the Case of New Hollywood}

The idea of film performance - understood in terms of the film itself as a performing agent, over and above the work of the human performers within it - has sometimes been evoked in the annals of contemporary film theory since the mid-1970s. For instance, Stephen Heath in Questions of Cinema:

Cinema is founded as the memory of reality, the spectacle of reality captured and presented. All presentation, however, is representation - a production, a construction of positions and effects - and all representation is performance - the time of that production and construction, of the realization of the positions and effects. ${ }^{2}$

For Heath, in this period of high-voltage theoretical activity, cinema was the "performing of time", a "ceaseless performance" of "subject-time" 3 - i.e., constructing a viewer who is 'held in' by a film. He speaks of "play then, but a play for: taken up in the film, the spectator is dispersed to be re-established in mastery - the apparatus is the availability of film's subject vision". ${ }^{4}$ And he provides a list of defining terms for mainstream narrative film: "The final time of film as narrative is that of identity, centre perspective, oneness, the vision of the unified and unifying subject, the reflection of that". ${ }^{5}$

What is missing from Heath's system? It is the sense of an active spectator who is precisely at play - particularly within the context of a loud, mass audience. Heath plumbs for a certain mode of zombiesque passivity in order to describe the general activity of viewers. I seek something different: an expanded, less constrained notion of play and playfulness; an appeal to those moments when an audience member has a strong, affective, participatory relation with a film - and with neighbouring viewers through the event of that film. Moments of participation and engagement that congregate around one fabulous scene, idea or splitsecond clinch, some memorable bit of business. These are not the arcane, fetishistic rituals of cinephile connoisseurship, but something that is very common, ordinary, everyday. The rest of this essay is an attempt to submit certain regimes of film theory to what psychologists call a reality-check or reality-test - evaluating it against a particular, on-the-ground level of commonsense movie experience.

Especially pertinent in this investigation is a large pool of contemporary productions since the early 1980s that are themselves highly performative, outrightly playful: John Hughes' teen movies, the action films of James Cameron and Walter Hill, the horror-fantasies of John Carpenter and Sam Raimi, even the most saccharine output of Steven Spielberg - basically, those films that define the New Hollywood cinema of the 1980s, at least in mainstream terms.

How are mainstream films different today from the heyday of its classicism between (roughly) 1930 and1960? The problem in theorising this domain arises from the absence of any unassailable "artistic modernism" in American cinema after 1960. There is a proud moment of 
the underground and its modest (but influential) incursion into features, via the New American Cinema of Shirely Clarke, John Cassavetes and Joseph Strick in the early to late 1960s; and there is a rash of surface effects of disruption, a scatty stylishness infecting a large range of American films in this same period, from Arthur Penn and John Frankenheimer to Norman Jewison and Stanley Donen - not to mention way-out-there satellites like Point Blank (John Boorman, 1967) and 2001: A Space Odyssey (Stanley Kubrick, 1968). But, in a very real sense, the fact that American cinema so quickly returned to business as usual - particularly by the time of Star Wars (1977) - makes it very hard for us to discern any decisive break or rupture in contemporary American cinema. But does that mean there is essentially no difference between "then" and "now", by the mid 1980s?

In a key reference text of the film scholarship canon, The Classical Hollywood Cinema by David Bordwell, Janet Staiger and Kristin Thompson, we find a definite, negative response to this issue. The authors note that classical cinema is defined and bounded by "unified narrative, motivated technique, and continuity devices"; it follows what is "utterly orthodox" in cultural production, which are the traits of economy, realism, unobtrusiveness, spectacle and narrative supremacy; and, furthermore, that current films "[perpetuate] seventy-year-old assumptions about what a film is and does" ${ }^{6}$

Again, the question arises: what is missing from this neo-formalist account of cinema, specifically mainstream, popular cinema? First, an audience; as Dana Polan comments in a critique of the 1970s work of Noël Burch, such an approach tends to posit a "formal spectator", an ideal or hypothetical construct, in place of any discernibly real viewer. ${ }^{7}$ Second, a sense that films can play up to their audiences, do turns, dance, play games beyond the protocols of what is strictly necessary for their cognition and comprehension as audiovisual narratives.

It often strikes me that the language of love or admiration that people use when they discuss their favourite moments and clinches in a movie closely resembles the language of the professionals who crafted these same films - how they must think out and go about what they do. Filmmakers (high or low) must consciously (as well as unconsciously or, more exactly, intuitively) approach the task of engineering special moments, great bits, memorable scenes: this is the essence of directing or shaping a performance (of whatever sort, actor performance or film performance). The type of living, dynamic relation to cinema I am evoking here - the relation to the amazing, performing film - is knowing, agile and complex.

\section{The Grand Tribunal}

We are observing a tribunal of our peers in the field of film studies, collected from several, diverse centres of interest in the field - it is a broad church. In the dock is contemporary, commercial, mainstream cinema. Let us reorganise the passing proclamations of our experts, which can be assembled into two categories.

First, there are ideas about how films work on audiences - and thus about what audiences actually are, and how people behave when they part of one. Andrew Britton, for example, wrote of Spielberg's Jaws (1975): “The film is inconceivable without an enormous 
audience, without that exhilarating, jubilant explosion of cheers and hosannas which greet the annihilation of the shark and which transform the cinema, momentarily, into a temple". 8 While, for Steve Neale referring to Raiders of the Lost Ark and the Star Wars cycle (adventure films or, more generally, special effects extravaganzas): "So many of these films are addressed, as it were, to a child-like adult, to a spectator consciously willing to adopt a naive position visà-vis events, characters and effects ... however terrified and astonished our look, it is a look solicited and fed by the film"..$^{9}$ This figure of the naïve, childlike spectator returns in Heath's description of what it means to see a film twice, five times, fifty times: "In order to see the film again, you need to forget it so as to have once more - so as once more directly to be - the memory it constructs you". ${ }^{10}$ The prospect for active spectatorship, as evoked in these accounts, is not terribly heartening.

In a second category, we encounter lists of what defines the mainstream fiction film as an aesthetic, formal object. For Neale on Raiders, "The 'relaunching of the cinematic machine' ... is evident in the film's deployment of narrative, suspense, adventure, spectacle entertainment". ${ }^{11}$ Tony Williams asserts, in the course of his analysis of Carpenter's Assault on Precinct 13: "It is a movie where analysis is subordinated to effect, enquiry to audience reaction, recognition of the implications of the material to non-political and non-ideological professionalism". ${ }^{12}$ Williams hastens to add that professionalism (the well-made, expert, even clever film) is not, after all a dirty word. But it is just as clear that, for many critics, it cannot exactly be a clean or innocent word, either. In fact, it is truly a lost word, consigned to immateriality and uncriticality - abandoned amidst the traces of "mere entertainment". It is the much the same in the case of Robin Wood. For him, Carpenter is "in many ways an engaging artistic personality"; his films "communicate, at the very least, a delight in skill and craftsmanship, a pleasure in play with the medium, that is one of the essential expressions of true creativity". ${ }^{13}$ But Wood then instantly accuses Carpenter's "film-buff innocence" of covering "a lack of real thinking" with "a formal/stylistic inventiveness that is initially irresistible". ${ }^{14}$

I do not think it is overstating the case to suggest that, for most of the critics or theorists I have so far mentioned in this essay, the terms they use define more or less a bad status quo of classical or mainstream cinema. Each characterisation of the film-object under scrutiny comes with an exemplar and, in an equal and opposite reaction, each posits a preferred type of cinema, again with an exemplar attached. For Bordwell, Staiger and Thompson, Coppola is the classical exemplar, with Yasujiro Ozu figuring as the fountainhead of a "rigorous formalism"; for Heath, Spielberg is the mainstream exemplar, posed against the radical disruptions of Michael Snow or Nagisa Oshima. In Neale's account, the seamlessness of Spielberg or Lucas is pitted against the "painful contradictions" we find in Martin Scorsese or Walter Hill; and for Williams, the innate conservatism of Carpenter is contrasted with the spirit of analysis and enquiry, the examination of social implications offered by a Larry Cohen or a Brian De Palma. 
Film performance, as I am defining it here, does not appear to have the right characteristics to fit any of these proposed alternatives to the mainstream norm. Rather, it very quickly and easily sinks in with the bad status quo; there seems nowhere else to put it.

Let's start over.

\section{Part II: Outline for a Theory of Film Performance}

\section{An Eight-Point Proposal}

I propose, as a speculative outline of a theory or model of film performance, a series of eight, gradually overlapping points that relate to both cinematic stylistics and audience response. They attempt to answer, from several different directions, that array of negative descriptions tabulated above from my Grand Tribunal.

a. A whole film can perform, at every level. Actors talking into camera, as in Ferris Bueller's Day Off, is only the most obvious instance of film performance. All levels must be considered in this light - music, pacing, mise en scène, plotting (the way a film lays out, withholds, pieces together plot information). In short, performance is a matter of every which way that a film can solicit the viewer or audience - its rhetoric.

b. Performance has very little to do with cinematic realism or naturalism. A performative film sequence is like a series of surfaces that gather and accumulate, bearing certain sorts of effects - let's call them effect-surfaces. A screen moment is thus more important for its register, its connotation or cue, its mood or feel, its level of intensity - than, say, its spatial consistency or the naturalism of its detail (let alone its meaning). The montage-sequence of mug-shots from Big Trouble in Little China is a typical example of this. A film performance is concerned above all with pitch, in the sporting sense - throwing balls of different sizes, at varying speeds, a few curve balls or swtich-hits included ... This is a model of film as a textual space (to revive, differently, Heath's valuable semiotic notion), marked by dynamism and volatility. Film performance is the event that happens between the audience (individually and/ or collectively) and the immediate fact of the coalescing of the cinematic materials. Thus, performance is not straining to be invisible or transparent, the state to which "classical" filmic conventions are often said to aspire - rather, it actively solicits the viewer.

c. Performative films actively court excess and a loss of strict narrative supremacy. "Court", because it is a matter of the film, as an event, becoming elastic, stretching itself out, but then easing back into line, never entirely snapping. So many prime performative moments are like a swelling inside the film, an acceleration or exaggeration of something already there as an undercurrent or overtone. Their pleasure often resides in the fact that they do not follow the plot line slavishly, but rather wander away from it for a while, suddenly re-directing it in some fanciful way. Moreover, performance treats fiction as an open system - and proceeds on the assumption that every developmental move in a fiction is basically fantastic, i.e., necessarily 
contrived or arbitrary. Popular fictional forms, generic plot formulae, stars and stereotypes, and so on, constitute a "game space".

d. Performance is not the same thing as spectacle or sheer display, while it contains that element. Throughout the first half of the 1980s, film theory has deployed a fairly monumental, Ben Hurscale notion of spectacle. But performance does not necessarily have to be overbearing or overpowering - the viewer does not have to submit to it, exactly. There are, as Sam Raimi's films prove, mighty performances that take place on the smallest levels of detail, gesture or style. In the avant-garde realm, the films of Marguerite Duras (such as Destroy, She Said, 1969) or the oeuvre of Michael Snow provide other instances of this phenomenon. In Williams' article on Close Encounters, he cites the climax of that film, its massive sound-and-light show, as prototypical of spellbinding, awe-inducing spectacle, both to the audience within the film and in our real space of the movie theatre. ${ }^{15}$ But, for me, this very same scene constitutes one of the supreme, performative moments of recent popular cinema: in the middle of all the sound-and-light happenings, there is a statement uttered by a stray character which, in relation to entire situation of phatic/sublime contact with alien creatures, is utterly banal and deflating: "What the hell are we saying?".

e. The film thinks with you and ahead of you; it works with your expectations. Here is a sequence of small but crucial conceptual/material steps. Performance presupposes two things: first, that as you view a film, you are thinking with it; and second, that at any moment of a fictional scene, there a number of possible moves a film can make. So, as you watch, you are trying to guess ahead (even if only intuitively) to the next move. This capacity to guess is based on a whole series of clues, or a whole chain of implications and inferences - "where can this film go next?", not only plot-wise, but mood-wise, camera-wise, editing-wise, music-wise. It is an ongoing question of "when will the next element fall into place?". So, it follows from this sequence of steps that a performative film will try to out-think you - to "fake out" the spectator, to use a term from magicians and cardsharps to which I shall return. This outwitting can take many forms: the film can try to fool or surprise you, or over-deliver on your expectations. A scene can play on what I have called an undertone in a scene by unexpectedly taking up and magnifying it - exploiting some latent, suggested or potential aspect it possesses. Recall Raymond Durgnat's advice: films have iceberg structures, "nine-tenths of it exist below the surface of the film, deep down in the spectator's own mind". ${ }^{16}$ Sometimes, in this process, as if the viewer's inner voice or thought-track has magically been seized and projected onto the screen, altering the progression of the filmic event itself.

f. The film is a stage, and cinema is a "movie theatre". It is productive to explore theatre metaphors in the attempt to describe the film-event. To imagine, for instance, that the performing film is itself a floating, mobile stage, with entries into and exits from this this scenography, and also an incessant play of the visible and the invisible, "on" and "off" spaces, what is on stage and what is in the wings ... Entries and exits (to stay with this particular trope for a moment) can be powerfully theatrical and expressive in cinema: think of (among many) Catherine the Great (Marlene Dietrich) in Josef von Sternberg's The Scarlet Empress (1934), Quinlan (Welles) and Tanya (Dietrich again) in Touch of Evil (1958); or the characters who emerge out of and back 
into dark doorways in Leone's Once Upon a Time in America (1984). Such movements and gestures mark the crucial dramatic and scenographic borders of the film-text. Performative films, too, have their own kinds of stage calls - they announce (in various ways) their own breaks (as in rap dancing) and moves. We see this most clearly in a certain kind of emblematic dialogue, whose function Philip Brophy has described so well. ${ }^{17}$ There are many kinds of "call lines" in popular cinema, from the "game time" and "let's party/kick ass/ rock'n'roll" exhortations of Aliens, to "fuck it, roll the dice" in Jim McBride's Breathless (1983) and the low dolly into Mel Gibson in Mad Max 2 when he intones "You want out of here, you talk to me". Performative films also often include their own running commentaries (most extremely in Bigas Luna's meta-horror-thriller Anguish, 1987) and brittle, fleeting epiphanies, lines such as "Not bad for a human" in Aliens - where the film becomes, for a moment, its own audience, internalising its implied, intended or imagined viewer.

g. Performance uses a set-up/pay-off structure. Let us recall the classic structure of a gag in comedy: set-up and pay-off. It can be extended to narrative structure in toto: elements are planted in the flow of the plot (what Heath calls the "narrative space") 18 that will later become crucial to the unfolding, or more usually the unblocking or resolution, of the action. There is an entire art in the planting and harvesting of such narrative procedures. Take the finale of Aliens; when Ripley appears in her make-shift armour, at first you kick yourself for not having noticed and stored in your mind the set-up when it was first planted (you forgot it in the whole, vast, intricate flow of film and its busy narrative events); and you especially kick yourself for not seeing that the set-up was about to be sprung at that exact instant (distracted from it by Newt's plight). In this context, we can say that a film's game is precisely to hide its next move from us. Is that what story plotting, in general, is all about?

h. Performance is all about timing. Here again, it is worthwhile experimenting with pertinent images from theatre. On the one hand, we might describe the film as a magician: your eye is keenly fixed on the movements of the trick, but still the magician is slipping things under your notice and into the event, which are eventually revealed. On the other hand, the film could also be thought of as a live comedian in a bar or theatre restaurant: a performer who has to work hard to hold in a tough, resistant, cynical audience. The success of winning over is not easily achieved in this situation; it is a difficult process of persuasion, in what amounts to a game or conflict of wits. In either variation, timing is the most essential element of a performance. And, in his own way, Heath is absolutely right about this: cinema is "the film itself, its time and its performance - its performing of time". But must we see the "institution" of this, as Heath implicitly does, as a "crime"? 19

\section{Faking Out and Moving Fast}

Finally, I offer a more general musing on the role of performance in culture at large. If my research on this score has an underlying impulse or motive, it is to move film criticism (for a few minutes, at least) toward showbiz - the intelligence of showbiz, the set of working intuitions which performers use "live". Within the history of showbiz, a very particular value 
is placed on performance. Indeed, I would suggest that one of the central conflicts of culture is between would could be called the "rule of truth" and the "rule of performance".

The rule of truth concerns direct speech, communication, authenticity, fidelity, truth to one's heart - saying what you mean and meaning what you say. Frank Capra's films provide an emblematic example of such a rule. The rule of performance, by contrast, values disguise, play-acting, mimicry. It sees performance as not merely an attractive activity, but more strongly an absolutely necessary and pragmatic one.

To put this schematically: where the rule of truth is liberal, optimistic and often nostalgic, the rule of performance is the urbane "rule of the city", assuming a certain treacherousness or decadence, sometimes in a highly cynical mode (as in the films of Ernst Lubitsch or Billy Wilder). Many classical films weigh up the delights and moral consequences of performance and then finally opt for truth - Preston Sturges' Hail the Conquering Hero (1944) provides a sinuous example. But for those artists whose sensibilities tend to the rule of performance, a certain, fascinating endgame inevitably looms.

To figure out this endgame, consider two fine moments in cinema history. The first comes from Walter Hill's action-comedy 48 Hrs. (1982), among the first of the popular "mismatched cop and crook" movies of its decade. It pits cop Jack (Nick Nolte) against crook Reggie (Eddie Murphy), and unites them in pursuit of a cop-killer. The film establishes a dramatic vector along the line of truth (Jack defends Reggie), until we arrive at this outburst from the police chief: "Just because you say it with conviction, it don't mean shit to me!" The second moment comes from Touch of Evil. This film pits a liberal cop, Vargas (Charlton Heston), against a corrupt trickster, Quinlan (Welles); the plot appear to pivot, for most of its duration, on Quinlan's likely frame-up of the suspect Sanchez (Victor Millan). In a key scene, Quinlan mercilessly interrogates Sanchez, and indeed tortures a confession out of him; he cries, "What do you want me to say? Yes, I did it". Vargas then leaps to the suspect's defence: "Would he say that if he really were guilty?" Quinlan's comeback is sublime: "Just because he acts a little guilty doesn't mean he's innocent". And it turns out that, in this instance, Quinlan, even though he did plant fake evidence on the poor guy, is absolutely right - Sanchez is guilty!

The rule of performance is wired up to this problem: under what conditions can someone or something be believed? (This is why so many performative films are, as if on principle, so unbelievable.) The rule seems to say: wherever we are, we are in a theatre, and you could possibly be having me on. In this sense, it is a principle of vigilance, suspicion, canniness (and, at its extreme point, paranoia).

Thus, performance is about bluff, about "faking out" or pretending, as Ferris Bueller often does - for instance, his mocked-up presence asleep in bed. Faking out is the art of advancing or staging one, explicit statement, while gambling on another that remains unspoken. Ferris teaches us something notable about performance-in-action, which relates profoundly to the aesthetics of popular cinema: faking out does not have to be particularly good or accomplished by any external, objective standard; it simply has to be operative, it has to work. 
Let us return one last time to our Grand Tribunal of critics who effectively argue: the surface of a Carpenter film is OK, it's good fun, but I know what's really going on under the surface, and therefore I know what the film doesn't know about itself! What a film usually does not know about itself, its "false consciousness" (or bad faith) according to this critical system, is that it is an ideological symptom - of racism, sexism, imperialism, capitalism. This is the regime of symptomatic analysis, prevalent since the late 1960s and the collective texts of Cahiers du cinéma on John Ford's Young Mr. Lincoln (1939) and Sternberg's Morocco (1930) ${ }^{20}$ - a "hermeneutics of suspicion" (as Paul Ricoeur identified it) ${ }^{21}$ which, at least in its basic outline or attitude, has today passed into the most ordinary kinds of culturally-informed reviewing practices in some sectors of the mass media.

Yet it is surely possible to pose to the symptomatic school the niggling thought that certain films internalise and reflect back their own pat readings, by a canny kind of popcultural osmosis. I think immediately of Body Double (1984), Videodrome (1983), Larry Cohen's The Stuff (1985), Big Trouble in Little China ... Cronenberg provides a remarkable example of this process, as does David Lynch in Blue Velvet (1986). The very existence of this phenomenon of movies' self-internalisation surely puts a spanner in the works of any simple, smooth critical apparatus that simply "reads off" ideological messages that are meant to be, first and last, happening unconsciously. What is the place of consciousness - the consciousness of showbiz performers, particularly - in all this? As always, the situation of a game - with its threat that some people in the match may be smarter than others by virtue of being more victorious - has the tendency to release hostile, defensive reactions; film and media culture, even at its highest intellectual levels, are full of such outbursts. ${ }^{22}$

But try to take the film performance position that I have been advocating here to its logical extreme. Let us entertain the possibility that there are films which fake out their critics/analysts like crazy. It is a dare situation: these movies lure their enemies closer, all the while hiding a gun behind their back. This particular dare dare involves, ultimately, the attribution of seriousness and meaning in a film - and about where exactly the critic presumes to locate these things in their workings.

Film performance, in short, dares us to think that films are sometimes smarter than we are, and to accept, work with that fact - which may not be, after all, such an awful realisation. 


\section{NOTES}

1. Noël Burch (trans. Helen R. Lane), Theory of Film Practice (London: Secker \& Warburg, 1973), p. 131. The fall that Burch evokes here is, in fact, stretched to almost forty seconds. He then goes on to describe another gag "elsewhere in this same film (the title of which unfortunately does not come to mind)" - it is The Heckling Hare (1941).

2. Stephen Heath, Questions of Cinema (London: Macmillan, 1981), p. 115.

3. Ibid., p. 116.

4. Ibid., p. 120.

5. Ibid., p. 122.

6. David Bordwell, Janet Staiger \& Kristin Thompson, The Classical Hollywood Cinema: Film Style $\mathcal{E}$ Mode of Production to 1960 (Columbia University Press, 1985), pp. 372-373.

7. Dana B. Polan, “Formalism and its Discontents", Jump Cut, no. 26 (December 1981), pp. 6366. Reprinted online at

[http://www.ejumpcut.org/archive/onlinessays/JC26folder/DistantObserver.html]. Accessed 31 December 2016.

8. Andrew Britton, Britton on Film: The Complete Film Criticism of Andrew Britton (Detroit: Wayne State University Press, 2009), p. 237.

9. Steve Neale, “Hollywood Corner: Raiders of the Lost Ark", Framework, no. 19 (1982), p. 37.

10. Heath, Questions of Cinema, pp. 121-122.

11. Neale, "Hollywood Corner", p. 37. The embedded phrase about the cinematic machine derives from Serge Toubiana, "Festival, Platform, Shop Window", Framework, no. 18 (1982), p. 33 - a text offering extracts from a Cannes Film Festival review by Toubiana in Cahiers $d u$ cinéma, no. 302 (July-August 1979), pp. 25-27.

12. Tony Williams, "Assault on Precinct 13: The Mechanics of Repression", in Robin Wood \& Richard Lippe (eds), American Nightmare - Essays on the Horror Film (Toronto: Festival of Festivals, 1979), p. 67.

13. Robin Wood, American Nightmare, p. 25.

14. Ibid., p. 26.

15. See Tony Williams, "Close Encounters of the Authoritarian Kind", Wide Angle, Vol. 5 No. 4 (1983), pp. 22-29.

16. Raymond Durgnat, "Towards Practical Criticism", AFI Education Newsletter, Vol. 4 No. 4 (March-April 1981), p. 10.

17. See Philip Brophy, "Read My Lips: Notes on the Writing and Speaking of Film Dialogue", Continuum, Vol. 5 No. 2 (1992), pp. 246-266. 
18. Heath, Questions of Cinema, pp. 19-75.

19. Ibid., p. 114.

20. See "John Ford's Young Mr. Lincoln: A Collective Text by the Editors of Cahiers du cinéma", Screen, Vol. 13 No. 3 (1972), pp. 5-44; and "Josef von Sternberg's Morocco" in Nick Browne (ed.), Cahiers du cinéma Volume 3: 1969-1972 - The Politics of Representation (London: Routledge, 1990), pp. 174-186.

21. See Charles F. Reagan \& David Stewart (eds), The Philosophy of Paul Ricoeur: An Anthology of His Work (Toronto: Beacon, 1978), pp. 213-219.

22. See Barbara Creed, "A Journey Through Blue Velvet: Film, Fantasy and the Female Spectator", New Formations, no. 6 (Winter 1988), pp. 97-117. In this ingeniously argued text, Creed asserts that the film's display of theoretical knowingness is a species of "bluff", upon which the vigilant, ever-suspicious critic must now call a "double bluff". 